\title{
An Effective Communication Model for Effectual Leadership in Educational Institutions in Kingdom of Saudi Arabia
}

\author{
Sivakumar Abirami ${ }^{*}$, Alobaidan Noora, Alsaleh Afnan \\ Jubail University College, Kingdom of Saudi Arabia
}

\begin{tabular}{ll}
\hline DOI: $10.36348 /$ sjbms.2019.v04i12.007 & | Received: 18.12.2019| Accepted: 25.12.2019 | Published: 28.12 .2019 \\
*Corresponding author: Sivakumar Abirami &
\end{tabular}

\section{Abstract}

Various researchers have discussed about the styles of leaderships and their ways of communication within the organization among various levels of professionals. This study intent to define the successful style of leadership that is suitable for educational institutions and the type of communication required for the success of the Higher Education institutions. Education though not a business is very competitive today. If there is no proper communication among the three levels of the Management, the success of the institution is debatable. The paper aims to design the dimensions of communication starting with the Top level - Principal/College head, Middle Level - Department head/Chairperson and Bottom level - Faculty members (Professors/Associate Professors/Assistant Professors/Lecturers). Though there are many people above in the Management like CEO/GM/Correspondent and End receivers' who are the most important stakeholders: Students. But the study focuses only on above mentioned 3 levels as there is huge need to communicate most of the time, among themselves as a team. This study is has identified these three levels of employees in educational institutions as Scholars, who directly contribute to the success of the institution. The objective of the study is to develop suitable leadership style and communication system that can develop trust among the scholars. It is essential for institutions that are evolving and changing for various reasons such as Vision 2030, Accreditation, Competitiveness and achieving global standards.

Keywords: Communication model, Interactive Leadership style, Scholars.

Copyright @ 2019: This is an open-access article distributed under the terms of the Creative Commons Attribution license which permits unrestricted use, distribution, and reproduction in any medium for non-commercial use (NonCommercial, or CC-BY-NC) provided the original author and source are credited.

\section{INTRODUCTION}

The leaders in educational institutions has to have a mixed style of leadership and communicate carefully according to the situation and context. The number of research on these lines are very few. Despite the close association between leadership and communication, it is surprising that little research has been done to operationalize supervisor-subordinate communication - specifically in a leadership context [1, 2] - except for studies looking at the delivery skills and speech content of presidents or prestigious business leaders [3, 4]. Communication shows the Scholar's attitude, behavior and has a high impact on the output. They have to use the right leadership and communication style to have a positive influence on the scholars.
This study has two research questions:

RQ1. What leadership style and communication fits the education institutions? $R Q 2$. What are the components of Effectual Leadership?

To make an effective communication, the scholars should be an Effectual Leader and on the other hand effectual leaders make effective communication that makes the receiver act immediately upon the instruction. The purpose of this study is to identify the right proportion of various leadership styles and communication competency required to achieve the desired result in the institution. 


\section{Need for the Communication and Leadership model} for educational institutions

Understanding human behavior; facilitating the reduction of social and cultural barriers to working together; and building capacity for faculty members to deal with complex, dynamic, and often conflicting teaching and administrative tasks or accreditation processes is quite a challenge. This requires a deep understanding of what 'drives' Scholars, their aspirations, their values, and their principles in life, and how development is linked to the personal and collective potentials of the teaching fraternity. The faculty members in todays' educational environment is torn between many tasks apart from teaching. The key is all about unblocking and creating social energy through facilitation that feed the social energy that can be generated through participation in the form of bottom-up development, decentralization and empowerment.

\section{General barriers for Scholars while communicating:}

- The need for a practical methodology or framework to measure how well the scholars are communicating that has high- impact among the chairpersons and faculty members.

- The need for dealing with conflict management, decisive problem solving and self-awareness among the scholars.

- The need for flexibility in changing contexts, and diverse target audiences.

- The need for frameworks and tools that align with workplace practice needs of an organization to ensure value-added outcomes.

Unfortunately, communication capacity for this type of creating overall participation is often lacking in educational institutions. Thus, one key to encourage such participation is to design the communication skills for educational institutions. In fact, there are many forms of communication skills and leadership styles that are prevalent, this study wants to verify the successful combination of leadership style and communication competency that influence scholars to make the educational institution a successful one.

\section{REVIEW OF LITERATURE}

For understanding the situation, motivating the scholars at the various levels the college head or chairperson of the department has to inculcate trust among the scholars. To become a great leader, the scholar has to use proper communication, say effectual communication. The following research papers gives an idea for this research paper based on the research gap, the research objectives are framed for this study:

For a leadership, high-impact communication is an essential practice, which composes of six elements, to achieve the desired results and add economic value. This article suggests a framework for practice-oriented high-impact communication. First component is speaking, understanding the audience, and composing the message accordingly [5]. The second component is speaker's communication filter. At this stage tailoring the message by taking into account some variables such as cross- cultural perceptions, attitudes, and educational levels, is essential to affect your audience. The third component is the message, the content and how it is delivered. It is significant to ensure that the message is clear and matching the audience attitude. The fourth component is target audience communication filter based on their beliefs, experience and perceptions. The fifth component is listening and feedback by making an eye contact, asking open-ended questions, and paraphrasing the target audience's words. The sixth component is "IntentImpact Confirming and/or clarifying the speaker's intentions to communicate for the desired impact (intent equals impact). An effective high-impact communicator ensures that the intended message(s) have reached the desired impact on the target audience" [6].

There are various theories and styles of leadership and in order to determine which style is effective certain factors should be evaluated. Some considerations are size of institution, degree of communication, and level of decision-making. The authors of this article suggest that "the benefits of accepting effective leadership principles and styles in school management have been proven to be of momentous worth by providing educational institutions with a holistic approach to coherently run the affairs of school management; offering benchmarking opportunities with others both within and outside of a school system, and creating structures and processes and establish relationships which enable teachers to engage fully in teaching" [7].

The usual habit of the leader is to foster intrinsic motivation within followers and match their personal goals to organizational ones. Role modeling and verbalization is the main focus of this leadership style. Bass [8] and Avolio [9] defined it as leaders who emphasizes on motivation, loyalty and commitment to drive the success of the firm. A good example is Steve Jobs who directed the transformation of Apple company through his superb qualities such as charisma and inspiration [10, 11]. The model of transformational leadership has been studied and implemented in banks, hospitals, schools and many others. Chipunza and Gwarinda [12] looked into how the application of transformational leadership model led to a merger between two high institutions of higher education in South Africa that has influenced positively on employees.

Transformational leaders can stimulate, alter, and encourage the strengths of the subordinate. An effective transformational leader recognizes and supports subordinates' needs, vision, self-confidence, and inner strength. A transforming leader will do the 
right thing, so it does not need to be popular or accepted, and avoid using authority and power to force followers' compliance. Every organization has a culture-defined in terms of core values, basic philosophies, and technical, financial, and humanistic concerns [8] - and transformational leaders work to change how to view such a culture through organizational policies, norms, and values.

A transformational leader demonstrates autonomy, hope, ethics, vision, and dedication [13], as well as charisma and inspiration [8]. Charismatic leaders can motivate an unquestioning loyalty and devotion without regard to one's self-interest within their followers. During states of crisis, emotional disturbance, or when organizations are transitioning, Charisma is most evident.

Inspiration instills arousal and heightening of motivation among followers [8]. Inspirational leaders are not reliant on charisma but on self-generated emotional feelings and sentiment. Inspirational leaders, like charismatic leaders, lack inner conflict and use emotional support and appeals, stimulating motivation in order to transcend self-interest [8]. Effective inspirational leaders appeal to one's sensation and intuition and emphasize persuasive appeals to faith rather than reason. Characteristics of inspirational leadership behavior include the ability to stimulate enthusiasm, build confidence, inspire belief in a common cause, and use a variety of other individual and institutional practices to emotionally arouse subordinates.

For transformational leader individualized consideration allows each subordinate to be treated differently according to one's individual needs and capabilities. In fact, individualized consideration is an important aspect of leader-member relationship or exchange, which makes leaders friendly, informal, close, and approachable. Effective leaders set an example to be followed, and significantly alter their followers' abilities and motivations [8]. There are six ways a leader can use individualized consideration: delegation, promotion, communication, treatment, counseling, and mentoring.

Intellectual stimulation, the last component of Bass's [8] transformational leadership model, is said to heighten efforts within subordinates. Intellectual stimulation generates problem awareness and problem solving, thought and imagination, and values and beliefs. Intellectually stimulating leaders concentrate on strategic thinking and intellectual activities in tasks of analysis, formulation, implementation, interpretation, and evaluation. Organizational executives using intellectual stimulation are able to discern, comprehend, visualize, conceptualize, and articulate the opportunities and threats to the organization and determine the organization's strengths, weaknesses, and comparative advantages.

Job satisfaction can be enhanced through transformational leadership [14, 15]. In Florida, nurses who were guided by transformational leaders actually were enjoying work at most [14]. Aggression can be experienced in work if improper leadership style was taken, high percentage of work stress, scarce resources or even low compensation, which will eventually result in low satisfaction rates [15]. Korkmaz revealed that high satisfaction rates among teachers can be achieved through the showcase of transformational leadership among top management, which positively influences their self-confidence level.

The leadership theory of Bass's [8] and Avolio's [9] possess three major components: transactional, laissez-faire, and transformational leadership. When a leader shows no relationship with subordinates is known as laissez-faire leadership, which is the least effective leadership [9]. Inactivity, irresponsibility, unaccountability and absence cloud over this type of leadership leaving an uncaring and heartless attitude among subordinates [9]. Baumgartel [16] investigated specifically through the organizational leaders of department of research and development (R\&D) and discovered that they possess the laissezfaire leadership to hinder innovation and creativity in science. This contributes to both low satisfaction and production among all followers and thereby affecting the growth and success of the company.

The demonstration of employee involvement, task delegation and personal relationships between the leader and the subordinates is known as transactional leadership. Transactional leaders often implement on subordinates one of the two practices: contingent reward or management by exception. Through being directive and authoritative, leaders can assess the performance of subordinates and decide which practice to pursue $[9,8]$. Contingent reward practice usually involves a relationship that focuses on praises, encouragements and inspirations. On the other hand, management by exception tends to focus on pointing out poor performance, giving negative feedback and monitoring insufficiency and deficiency.

Seidman \& McCauley [17] investigated through the styles of leaderships and discovered that transactional leadership is more effective and successful than laissez-faire leadership. However, transactional leaders are found to be less creative and innovative [9]. Bass [8] found that if an operation is wrongly conducted thereby negatively affecting an organization or even a showcase of distrust and animosity, transactional leadership is the usual style to be possessed by leaders. 
Communication competency required for various styles of leadership in Educational Institutions

Academic communication needs to be effective, accurate and distinctive. The leadership traits can be identified with scholar's characteristics, personality and charisma that she/he possess. Scholars perform lot of tasks based on their positions. The important thing is to identify the right kind of communication for conveying the sensitive issues. What is expected of the chairperson or College deputy is how they are motivating the team and fulfilling the tasks that are academic and administrative documentations. Educational institutions have lot of documentation that are essential for Accreditation bodies, Ministry of Education, Global competitors and Top Management. Right communication is the only tool to promote trust among the scholars that they will be recognized for their contributions and rewarded.

The Conceptual Model for Effective Communication of Effectual Leaders given below shows clearly the style and communication types and purposes to be chosen for success of the Educational Institution:

Let us start from the CEO/General Managers/Correspondents of educational institution, they are the promoters and top management of the institution and are concerned with creation of the
Vision, Mission and Strategic Goals. They follow Laissez-faire style of leadership often. Though it is said to be one of the least effective leadership style as these top management doesn't give any instructions or guidance, their non-interference in the planning, coordination and implementation of the institution goal as per the vision and mission decided by them. This helps the College deputy/Principal to work out the broad outline for the institution and implement with the help of the scholars such as Chairpersons and Faculty members. They are Authoritarians and Visionaries and prefer verbal communication most of the time to give instructions in their meetings.

College Deputy/ Principal are Transactional Leaders as they just want to implement what their leaders decided. This level of the scholar gives less guidance and most often tries to create the fear of failure and penalty. If the process did not achieve the desire results, say for example achieving the Program objectives by the chairperson. During the academic year, students could not perform well and this eventually will affect the chairperson where his/her productivity will be questioned. If such actions are taken distrust and animosity will overwhelm the organization's environment.

A Conceptual Model for Effective Communication for Effective Leadership

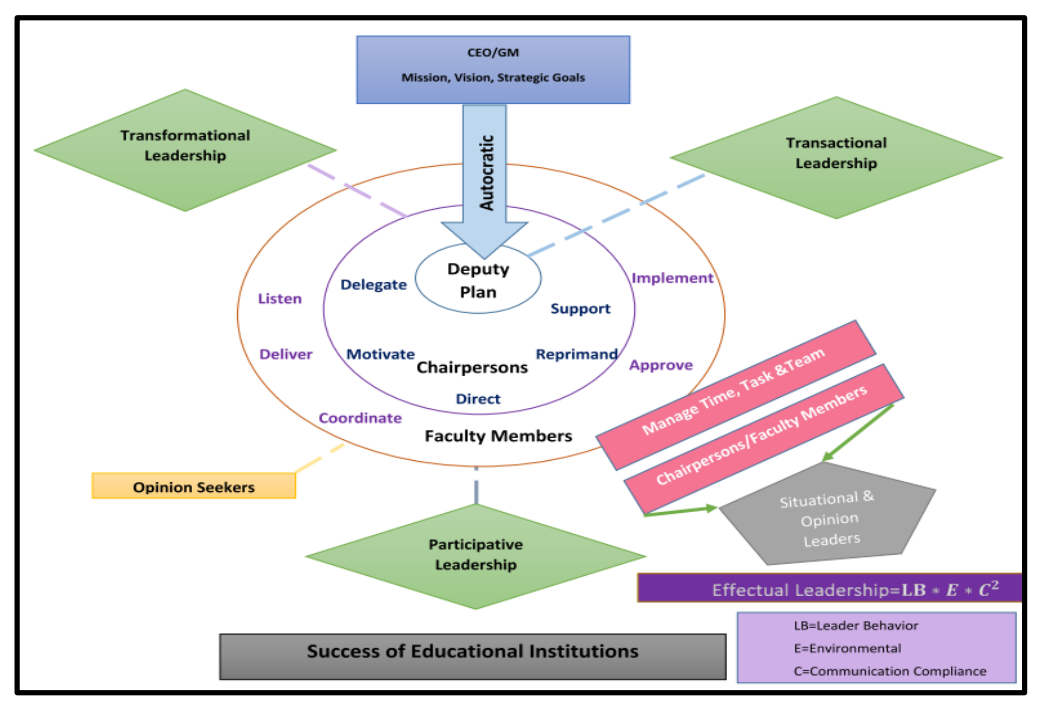

Chairpersons/ Heads of the department needs intercultural communication skills that are triggered by new communication technologies (such as the mobile, e-mail, twitter, Instagram, Black board (LMS) etc.), to delegate, motivate, direct the Faculty members to accomplish the academic and administrative work on time. The chairpersons are the Transformational leaders who emphasis the need for international curricula, national and international accreditation to remain competitive in a global educational system. A prerequisite for successful educational institution is the development of intercultural competence among various educational institutions' levels with various faculty members who come from various culture and society. In case the faculty member does not perform they have to reprimand them to enhance their productivity. This transformational leaders' behavior is the most important component of Effectual Leadership. As Transformational leaders they articulate clearly and motivate the scholars to achieve the vision and mission of the institution. They Inspire trust and respect among the scholars and Connect with others individually and in teams to accomplish tasks, skillfully guide others to act immediately with confidence and Possess a positive 
ethos. They follow affiliative style to achieve the educational objectives of the institution.

Faculty members the Participative leaders who are opinion seekers and sometimes opinion makers. Their emotional intelligence and communication skills, are directly related to the success of the Educational Institutions. Their awareness of the responsibility, understanding of the regulations, helps them to Coordinate, Deliver, Listen, Approve and Implement the set goal. These two scholars the chairperson and the Faculty members work together on the Task, Time and Manage Outcomes. They together form Situational Leaders. Their Emotional Intelligence and Emotional Quotients help them to create better educational Environment.

\section{CONCLUSION}

As per the objective of this paper the style of leadership and communication required among the scholars have been identified and how communication style has to vary from one style of leadership to another in educational institution depending on the situation has been confirmed. Effective Communication makes the leader, effective leader. The model shows the relationship between communication and compliance in educational environment with ideal Leaders behavior.

Hence the study shows how the scholars can progress and become Effectual Leaders.

Effectual Leadership $=\mathrm{LB}^{*} \mathrm{E}^{*} \mathrm{C}^{\wedge} 2$

Where,
LB stands for Leader Behaviour
E stands for Environment and
C stands for Communication and Compliance

On the basis of the above discussion Trust can be achieved by Leaders Behaviour in the educational institution. Once they scholars have trust the communication among them becomes effective communication that leads to compliance.

\section{LIMITATION}

Due to the complexities of educational institutions and scholars involved there are several limitations to the present study. The most important limitation is the model has not been directly tested on the three levels of scholars but is based on observation, inquiry and unstructured interviews. The gender, culture, emotional factors, attitude and expectation differ and the model cannot be completely reliable and valid for all.

\section{REFERENCES}

1. De Vries, R. E., Bakker-Pieper, A., \& Oostenveld, W. (2010). Leadership $=$ communication? The relations of leaders' communication styles with leadership styles, knowledge sharing and leadership outcomes. Journal of business and psychology, 25(3), 367-380.

2. Penley, L. E., \& Hawkins, B. (1985). Studying interpersonal communication in organizations: A leadership application. Academy of Management Journal, 28(2), 309-326.

3. Bligh, M. C., \& Robinson, J. L. (2010). Was Gandhi "charismatic"? Exploring the rhetorical leadership of Mahatma Gandhi. The Leadership Quarterly, 21(5), 844-855.

4. Emrich, C. G., Brower, H. H., Feldman, J. M., \& Garland, H. (2001). Images in words: Presidential rhetoric, charisma, and greatness. Administrative Science Quarterly, 46(3), 527-557.

5. Shlien, A., Campbell, B. B., De Borja, R., Alexandrov, L. B., Merico, D., Wedge, D., ... \& Pollett, A. (2015). Combined hereditary and somatic mutations of replication error repair genes result in rapid onset of ultra-hypermutated cancers. Nature genetics, 47(3), 257.

6. Kerns, C. D. (2016). Decisive problem solving: A key leadership practice. Journal of Management Policy and Practice, 17(2).

7. Amanchukwu, R. N., Stanley, G. J., \& Ololube, N. P. (2015). A review of leadership theories, principles and styles and their relevance to educational management. Management, 5(1), 6-14.

8. Bass, B. M. (1985). Bass Transformational Leadership Theory.

9. Avolio, B. J. (1999). Full leadership development: Building the vital forces in organizations. Thousand Oaks, CA: Sage.

10. Scott, E. B. (2003). The Role of Transformational and Transactional Leadership in Creating, Sharing and Exploiting Organizational Knowledge. Journal of Leadership \& Organizational Studies. 9(4):32-44

11. Bass, B. M., \& Riggio, R. (2005). Transformational leadership: Second edition. 1282. 10.4324/9781410617095.

12. Chipunza, C., \& Gwarinda, S. A. (2010). Transformational leadership in merging higher education institutions: A case study. SA Journal of Human Resource Management, 8(1), 1-10.

13. Burns, JM (1978). Leadership. New York: Harper and Row. Leadership Quarterly, 2(1).

14. AL-Hussami, M. (2008). A Study of Nurses' Job Satisfaction: The Relationship to.

15. Korkmaz, M. (2007). The effects of leadership styles on organizational health. Educational Research Quarterly, 30(3), 23-55.

16. Howard, B. (1956). Leadership, Motivations, and Attitudes in Research Laboratories. https://doi.org/10.1111/j.15404560.1956.tb00365.x

17. Seidman, W., \& McCauley, M. (2011). Transformational leadership in a transactional world. OD practitioner, 43(2), 46-51. 